\title{
How (Fictional) Politicians Persuade and Manipulate Their Viewers? The Case of House of Cards
}

Preliminary communication _ DOI 10.22522/cmr20170224 _ received on 18 June 2017 UDK 65.012.12:7.097(05 - 32-057.34:654.197(05)

\section{Irena Sever Globan}

Catholic University of Croatia, Department of Communication, Croatia. Email: irena.sever@unicath.hr (corresponding author)

\section{Marko Ezgeta}

Croatia. Email: m.ezgeta1@gmail.com

\section{Abstract}

In times of increasing individualism when many traditional socialization institutions lose their primary role and influence, television series characters have become new role models that people can identify with. Modern television production is inclined to portray protagonists as antiheroes because viewers are more engaged and intrigued by them compared to the traditional protagonists. Series often break the so-called "fourth wall" in a way of transcending boundaries between virtual and real life, talking directly to the viewers, thus creating parasocial interaction. According to the transportation theory of persuasion, the greater the emotional bond with the characters, the higher the possibility for the viewers to "transport" within the narrative. This phenomenon can be particularly noticed in the political drama House of Cards, where the Machiavellian politician Frank Underwood persuades both characters in the story and the viewers in order to achieve some of his personal goals. The aim of this paper is to highlight the methods of persuasion and manipulation used by the protagonist in order to recognize how he wants to persuade us and recognize what his underlying goals are.

Keywords: television series, persuasion, transportation theory, political drama, House of Cards 


\section{Introduction}

Television series are media forms whose narration attracts increasing media audience attention as they have almost reached the quality of film production in the aspects of content and style, especially those produced in North America. It is not without reason that Italian television critic, Aldo Grasso (2007, p. 5), said that television has never been as lively, intelligent or rich as it is today. From the very beginning, in addition to providing the viewer a sense of enjoyment and an escape into the world of entertainment and fantasy, the television series tried to provoke an interest for current political and social themes and problems (Esquenazi, 2010). In this context, it is important to be reminded of Rod Serling's anthology series, The Twilight Zone (1959-1964), through which the author talked about numerous current political and social themes, such as the Cold War, human identity, alienation in the modern world, racism, new technologies and the crisis of democracy. Television stories influence social norms and form political opinions offering models for shaping personal and social identity to the recipients. According to those models, we often define what it means to be successful or unsuccessful, good or bad, masculine or feminine.

Horace Newcomb (1988, p. 88) claims that television series are the central storytelling system that serves the function of myths and fairy tales that were previously narrated by the street bards. The average person watches more television series in one weekend than a person who lived only a few decades ago did within a lifetime (O'Connor, 1989). That fact calls for a serious study of the television series phenomena.

Jean-Pierre Esquenazi (2009) considers that the audience expects that television series paraphrase the real world more than any other genre. With the help of fictional worlds and narratives, they evoke a real world, thus it is important that the series is in line with contemporary life and for the plot and the characters to show current events contributing to the bond of television and the present moment. In that way, the series follows changes in our reality, including ones considering political realities. Therefore, analysing a television series means trying to understand what the topics deal with in a given period of time, how they are related to the real social situation and even who are the heroes that are presented to the viewers as role models. Television allows society to become aware of its own problems, crises, beliefs and habits offering to an individual a variety of interpretive keys for a specific action (Fiske, Hartley, 1978, p. 89). That is why television is not defined 
solely as a "reflection of reality", but also as an "example" of how things are and how to behave. The so-called "duplicate of reality" that television sets and transforms through its serial characters is capable of modifying the socio-cultural system (Casetti, Di Chio, 2001, p. 267), both to bring hope to the world and to take it away.

In times of increasing relativism and individualism in which many traditional institutions of socialization are losing their primary role and influence, many television series characters become our new "media friends" and role models we can identify with (Buonanno, 2006, pp. 101-105). The heroes of these series mirror the socio-cultural reality and changes, but they are also often offered as models for imitating and shaping a new worldview. Lately, we are noticing the trend of modern television production using protagonists that are antiheroes, but the viewers nevertheless like them and empathize with them. Some of the recent villain protagonists that we "love to hate" are Dr House, Dexter, Walter White, Hannibal, Tony Soprano, Don Draper or Frank Underwood. Characters, such as the boss of a Mafia clan, a terminally ill high school chemistry teacher, a marketing guru who faked his entire life, a peevish doctor who excessively uses drugs, a serial killer who "only" eliminates the killers or unscrupulous politicians, attract viewers from all over the world. It seems like the modern viewer gets more thrills and enjoyment out of the stories about criminals and villains as opposed to the classical hero stories. In this sense, Bruce McKeown et al. (2015, pp. 152-154) explored the relationship of the viewers with the main characters of the crime drama Breaking Bad. Although the respondents knew the story of Walter White, they stated how they continued to support his actions, despite their awareness of the criminality and immorality of his actions. ${ }^{1}$ The question that arises is whether the new (anti)protagonists can influence the viewers to sympathize with crime and, consequently, the concept of moral relativism?

Another characteristic of a modern television series is that the characters often break the so-called "fourth wall" in a way of transcending boundaries between virtual and real life talking directly to the viewers, thus creating parasocial interaction and tighter bonds

1 Cynthia Hoffner and Martha Buchanan (2005, p. 342) tried to answer the question of what it is that mostly affects the identification with television characters and came to the conclusion that children and adolescents identify more with characters that they consider similar to themselves, i.e. that are the same gender and share the same attitudes. Male respondents thus identified with male characters that are portrayed as intelligent, successful, but also violent, while women identified more with successful, physically attractive, intelligent female characters as the female characters that were respected by other characters of a certain television series. 
with them. This phenomenon can be particularly noticed in the political drama House of Cards where the Machiavellian and unscrupulous politician Frank Underwood persuades and manipulates, not only other characters in the story, but also the viewers in order to achieve some of his personal goals: to climb up the top of a political ladder and to stay at that position as long as possible, taking any means necessary. Thus, he puts an end to the portrayal of positive politician protagonists who were the main characters of former television series and tried to make a world a better place by fighting against crime and corruption and convince its faithful audience that it is worthwhile to fight for ideals and the common good. We can reasonably ask the question of political and ethical values that a character such as Frank Underwood promotes through the series, during these times of severe political crises around the world. In order to detect the new paradigm of the portrayed politicians and politics within the television series programme one must include the methods of persuasion, manipulation and propaganda that are used. This paper will provide the results of a content analysis of certain episodes during the four seasons of the series in order to recognize what a fictional politician such as Frank Underwood wants us to be persuaded into.

\section{Politicall Drama and the House of Cards}

The fundamental determinant of a political drama is that the plot revolves around high politics and the characters are active protagonists on the political scene. The Script Lab (2016) states that the protagonist in this genre is usually in conflict with a corrupt political system while the stories are based on the events in the real world and often explore conspiracy theories. Some of the most prominent examples of political dramas in history are Tanner ' 88 (1988) and The West Wing (1999-2006). Although this genre has never been as popular as criminal, medical or legal television series, the recent trend of ever increasing interest in political drama has been growing, and in the first half of this decade some of the most watched series of this genre attracted millions of fans [e.g. Scandal (2012-), Borgen (2010-2013), The Good Wife (2012-2016), Political Animals (2012-), Veep (2012-), The Newsroom (2012-2014), and House of Cards (2013-)].

Since we were wondering how modern political series portray politicians and what the nature 
of their politics is, we have decided to analyse one of the most popular North American political television series, House of Cards, which captivated a global audience. It is noticed that the protagonists use numerous methods of persuasion, manipulation and propaganda, taking any means necessary in order to achieve their goals, making their communication a negative communication process. It seems as if the creators of the series want us to believe that democracy is actually a farce and that the citizens are only visibly free electors who vote for the politicians who will represent them and fight for a common good. House of Cards started broadcasting in 2013 and it is produced by the increasingly popular Internet television network - Netflix. The author of the series is Beau Willimon, to whom this is the first television project. As of 2016, four seasons of the series have been broadcast, i.e. 52 episodes overall. It is a political drama adapted from Michel Dobbs' book, House of Cards, which was screened for the first time in the form of a mini-series made by BBC television. When it comes to aesthetics, this modern television series does not fall behind cinemaproduced motion pictures and one of the reasons for this is that the cast and the crew of the series is mainly made out of people who previously worked in the film industry. In fact, the creator Beau Willimon is one of the screenwriters of the political drama film The Ides of March for which he was nominated for an Academy award. The main protagonists are played by well-known movie actors such as Academy Award winner Kevin Spacey and Golden Globe winner Robin Wright.

The contemporary political drama of House of Cards tells a story about the crisis and the unscrupulousness of the democratic political system of the "most democratic" country in the world, the United States of America, and the process of rising to the top of the political system. The protagonists are politicians who use all legitimate and illegitimate methods to achieve this goal, manipulating and assuring everyone around them that what they do is good and necessary; for them as politicians, for the citizens of the USA and, ultimately, for the world. The main protagonist of the series is Frank Underwood (Kevin Spacey), an American politician who was supposed to be nominated for the function of the US Secretary of State, but the newly elected president changed his mind at the last second. Resenting this unjust decision, along with his wife Claire (Robin Wright), he constructs a diabolical plan to rise to the most important political role in the country, the President. Frank Underwood does not fight a corrupt political system, as is usually the case in conventional political dramas. On the contrary, he makes the system even more corrupt. Throughout the four seasons, 
we follow Frank's Machiavellian climb up the political ladder: from the position of a party whip in the United States House of Representatives, to the position of vice president of the United States, and ultimately to the President. Through his political ascension, we also follow the changes in Frank's behaviour and how his actions affect his life, the life of the people around him, but also the American people in general, i.e. - how his actions affect the political system of the Western world.

The protagonists of this series are, therefore, anti-heroes who often try to justify their immoral decisions. Their acts are the direct consequence of the unfortunate life circumstances in which they were growing up or they live in. This is a well-known idea that Jean-Jacques Rousseau (1762/2008, p. 34) presented in his capital work The Social Contract. He claimed that the will (volonté générale) of man is always good and serves the progress of society and that people are essentially not evil. However, if they are often deceived by other members of society, then their will may be malicious.

\subsection{Breaking of the "Fourth Wall" and Parasocial Interaction}

It is not unusual to see the breaking of the "fourth theatrical wall" in today's films and television series. This occurs when characters turns to the camera, look directly at it, and address the viewers themselves. The French encyclopaedist, Denis Diderot, who have obliged the theatre and, implicitly, film and television, wrote about the breaking of the "fourth wall" in the $18^{\text {th }}$ century because of his efforts to change the traditional theatre of the time directly through the creation of the concept of the "fourth theatrical wall" (Stevenson, 1995, pp. 4-5).

In House of Cards, Frank Underwood directly addresses viewers and informs them of his actions, through the use of meta-references, thus creating deeper relationship with the viewers. ${ }^{2}$ An interesting example of the use of meta-references is the last scene of the first episode of the second season (Franklin, 2014) in which Frank looks at the camera and raises the question: “Did you think I'd forgotten you? Perhaps you'd hoped I had." He, then, commented on the reasons why he killed journalist Zoe Barnes and said to the audience:

2 Philip J. Auter and Donald M. Davis (1991) conducted research whether the viewers of humorous television series are more engaged if the characters break the "fourth theatrical wall". Their research showed that the audience feels more connected with the content of the humorous series and experience the humor more intense. 
"Welcome back." At that moment, he leaves the scene and the camera slowly comes down to the suit cuffs he had previously received. His initials, namely, letters F and U, are written on them. It can be assumed that this greeting is not his last, given that the viewers from the English-speaking world are very aware of the hidden meaning of the letters $\mathrm{F}$ and $\mathrm{U}$. Even though Frank Underwood is the only character who uses meta-reference throughout the seasons of this television series, we see a change in the last scene of the last aired, $52^{\text {nd }}$ episode (Verbruggen, 2016). Taking into consideration the plot of the series and Frank's understanding that, without Claire, it is impossible for him to succeed in politics, we are witnessing her breaking the "fourth wall". While the two protagonists are not completely equal as Frank is the only one who talks to the viewers saying the hard words: "We don't submit to terror. We make the terror." Claire, non-verbally, supports him in what he says. The next moment they exchange glances and both look at the camera and in that way she confirms that she is aware that they are being watched.

Such addressing to the viewers contributes to the formation of a parasocial interaction between media consumers and media protagonists, the phenomenon that Donald Horton and Richard Wohl (1956, p. 215) wrote about in the fifties of the $20^{\text {th }}$ century. Parasocial interaction deals with the feelings of the consumers of the media content who create an illusion that they are in a genuine social interaction with media characters (Horton, Strauss, 1957; Hartmann, Goldhoorn, 2011; Dibble et al., 2016). The medial mediator always takes on the role of the sender of the message and the consumer is considered the receiver. Nevertheless, the receiver experiences the encounter as immediate, personal and feels that the communication is symmetrical (as cited in Hartmann, 2016, pp. 131-132). Parasocial relationships that are created between media characters and the public can be manifested in different forms, from extreme adoration, romantic feelings and friendly admiration to intolerance towards the characters we do not like. In that way, parasocial relationships are characterized as ordinary social relationships between people (Branch et al., 2013; Lakey et al., 2014). Moreover, the greater exposure to media content and the characters, the stronger the relationship with the audience will be. (Bond, Calvert, 2014; Schiappa et al., 2007). It is interesting to point out research by Keren Eyal and Jonathan Cohen (2006) that showed how the undesirable break up in parasocial relationship can create a sense of sadness and abandonment, just as breaks up in real relationships (as cited in Hartmann, 2016). 
The Internet and the social networks contribute to the creation of parasocial relationships between the characters of a certain television series and their viewers. Modern media allows fans to be more engaged and to influence directly the content of television series. The communication with the fans on the official House of Cards Facebook page is as if the characters of the series truly exist in our world and Frank Underwood is the current President of the United States. More than two million people follow the content of this site and many who comment directly address the characters as their (virtual) friends.

\subsection{Persuasion, Manipulation and Propaganda in House of Cards}

Persuasion, manipulation and propaganda are nearly synonymous; the only differentiation is in the intention of the communication process (whether is it positive or negative to the recipient of the message) or if the messages are aimed towards an individual or a group of people. Thus, Richard M. Perloff (2002, p. 34) defines persuasion or manipulation as "a symbolic process in which communicators try to convince other people to change their attitudes or behaviour regarding an issue through the transmission of a message, in an atmosphere of free choice”. Rom Harré (1985, pp. 126-127) differentiates manipulation from persuasion according to the fact that a person who is manipulated is not aware of the influence that is exerted upon him, making it a negative communication process. While successful persuasion can benefit both the recipient and the sender of the message, the goal of manipulative messages is to solely benefit the sender of the message. Those are the facts that represent the ethical and moral problems of undesired influence on the attitudes and behaviour of another person when it comes to manipulation. John Stuart Mill stated that the power, in this context the power of speech, can be used legitimately against another person only in the event of the potential damage that an individual might make to himself or to members of society. In the end, this would mean that the goal still justifies the means, not always and everywhere, but only in the specific circumstances in which, between the two evils, the one that is causing less harm should be chosen.

A term often associated with persuasion and manipulation is propaganda. Anthony Pratkanis and Elliot Aronson (1992, p. 8) define propaganda as "the communication of a point of 
view with the ultimate goal of having the recipient of the appeal come to 'voluntarily' accept this position as if it were his or her own". Explaining propaganda, Noam Chomsky and Edward S. Herman (1988, p. 2) emphasize the importance of mass media and state that today's mass media outlets have an important function for powerful groups, such as global corporations. The term they have coined - "manufacturing consent" - comes from several filters that affect the formation of a message that is propagated using mass media. The size, ownership and drive for profit of mass media institutions, the sourcing of mass media news or negative responses to a media statement or program affect the design and dissemination of a propaganda message that ultimately affects the political economy of society; on the other hand, Edward Bernays (1928, p. 20) considered propaganda not necessarily a negative term. As he states, it depends on the context and the truth of the information being promoted.

There are many theories of persuasion studied by social psychology, and for the purpose of this research, we have decided for one of the most reputable, i.e. transportation theory, which analyses persuasion in media narratives. Namely, Melanie Green and Timothy Brock (2000, p. 701) argue that consumers of media content are, to a greater extent, exposed to public narrative than public advocacy. That is the reason their work focuses on research of public narratives, more precisely the one in novels, magazines, music or television. Their fundamental research question is the extent to which a media user will transport to the narrative world and connect with characters from the fictional world. To explain their theory, they refer to the idea of a mental process that at the same time combines the attention, the imagination and the feelings, so the authors refer to the feeling of "losing within the story”. Chun-Ting Hsu, Marcus Conrad and Arthur Jacobs (2014, p. 1359) used the Harry Potter books as examples to prove that narratives that contain an amplified emotional context affect the empathy of the reader, resulting in stronger brain activity. Authors have confirmed in the study that emotional content, particularly a negative or exciting one, activates affectionate empathy and recipients of communication messages make it easier to engage in content, thus creating a special reading experience. According to Green and Brock (2000, p. 702), consumers of media content, when immersed in the narrative world, lose contact with reality both physically and mentally. The experiments of these authors (2000, p. 719) have proved that people are more inclined to transport into a narrative if they consume fictitious highly produced content versus the realistic ones. The research 
conducted by Tom Van Laer et al. (2014, pp. 797-802) shows that transportation into a narrative can cause cognitive responses such as change of thinking, mode of action and attitudes of a recipient. The authors emphasized that the degree of empathy depends on the identification with the character of the fictitious narrative and that emotional element allows for the transition to a fictional narrative. It is noticed that the creation of special, almost friendly, relations between the characters of the television series and the viewer can directly influence that, what they see and hear in television series, is taken for granted, without much critical reflection.

\subsection{Methods of Persuasion, Manipulation and Propaganda}

Communication science is familiar with numerous persuasion methods ${ }^{3}$ and for the purposes of this research we have selected 27 of them. Most of them are taken from the publication Persuasive Language in Media Texts by Iris Breuer and Melanie Napthine (2008, pp. 75-78). In the following paragraphs, a short explanation of all the methods taken by the named authors will be explained.

Analogy is a method of persuasion in which a certain thing or situation is compared with another, and the effect of the method is to explain a complex point in more familiar terms. Anecdote is interpreted as a short, personal story that is often entertaining or comical and as it is being presumed the story is true, it carries the weight of credibility with the consumer of the message. Appeal to family values is based on the idea that the traditional family arrangements are the best for the individual and the society itself. Its effect is to cause the reader to agree with this idea and to recognize any different family arrangements as the one that might hurt the essence of the society. Appeal to the law and a sense of justice speaks to the belief that we are all equal in front of justice and that we all deserve the same treatment. The effects that this method might cause are creating the idea that punishment should fit the crime and increasing anger if the injustice is noticed. For this research, this method is extended to an appeal to the law, especially laws of the country and the consequences if those laws were to be broken. Appeal to hip-pocket nerve is associated with the human need for a sense of financial security. This method encourages

3 Since the methods of persuasion, manipulation and propaganda do not differ, in parts of the text where only the persuasion method is mentioned, it is referred to as persuasion, manipulation and propaganda. 
strong emotions, for example rage if a person feels financially exploited. A recipient of a message may also feel vulnerable to those who create financial policies. Appeal to selfinterest presumes that someone's personal interest should be placed ahead of the interests of others; this method often creates a division of people into "us" and "them" and stimulates the creation of feelings that the interests of others are competitive to our own and thus endangered by them. Appeal to patriotism relies on the national pride and loyalty of the people, the recipient of the message gets the feeling that he is not loyal to his own country unless he agrees with the sender of the message. The use of this method invokes the powerful emotions of pride, guilt, loyalty and even anger or fear. Appeal to group loyalty exploits the human need for a sense of belonging. Using this method, feelings of guilt, responsibility, fear and sentimentality are exerted by the recipient of the message. It assures people that the group depends on their support; it often comes with the method of usage of inclusive language. Appeal to tradition and custom puts a high value to history and to someone's background. It presumes that moving away from tradition and customs can be damaging to the society. The effect of this method is encouraging the recipient of the message to resist changes and create feelings of retention of past values that are often romanticized. In the absence of logical arguments some try to appeal to emotions; the sender of a message inclines to control the emotions of the recipient and often generates a sense of guilt, insecurity and need for a change. The response to the message is, therefore, quite emotional, rather than rational.

Evidence is the following method of persuasion, manipulation, and propaganda explained by Breuer and Napthine and this method includes facts, information or opinions of experts that can be used selectively in order to further reinforce the arguments. Usually, the source is relevant and it offers the sender of the message the possibility of greater credibility. Generalization is presenting the facts in a way that suggests that something is true for most people just because it is sometimes true. In this method, an appeal is made to certain stereotypes, prejudices and already acquired attitudes. Connotation is characterized by emotional connection with the meaning of the word. The persuader often uses synonyms for certain words to which positive or negative connotations were added. To detect this method it is important to know the communication of the group since the same term for two different groups can have a completely different meaning, no matter the fact the same words might be used. Attack on a personal level is used to discredit the opponent and it 
includes a personal way of thinking about the character of an individual. The use of this method draws the attention away from the relevant topics and arguments, and with the observer of the communication, creates a feeling of distrust towards the person and claims of the person to whom the attacks are directed. Repetitions relate to repetition of words, phrases, sentences or ideas in order to emphasize the message. This method is suitable for directing attention and achieving a clear memorization of the message. Overstatement means using a linguistic figure of hyperbole to exaggerate the true situation. This method is used for intimidation, dramatization or even for humorous purposes. Rhetorical questions are questions in which the answer is usually known. When using this method, the recipient of the message is placed in the position of agreeing with the sender of the message as it is assumed that the response is already known. The use of clichés, or too many used phrases that are known to most, serves to transfer meaning and the point of communication in a fast and efficient way (most people understand them) and create a sense of understanding. The usage of inclusive language refers to the use of words like "we" or "together", which include a person in a certain group. Using this method creates a sense of communion, belonging and responsibility.

Other used methods in this research were taken by various authors and were added to the research. Appeal to fear and insecurity is based on the assumption that the worst outcome of the situation is possible and real. Bennett (2012) emphasizes the human need to undertake preventive measures to avoid the worst outcome. Thus, this persuasion method must be recognized and responded according to probability, rather than a possibility. Humour as a method of persuasion, manipulation and propaganda is used in a variety of ways: using puns, sarcasm, irony, telling jokes, etc. Carmen Moran (1996) states that the use of humour in persuasion has an emotional impact on the audience, and serves as a method of relaxation of the recipient of the message (as cited in Rod Martin, 2007, p. 137). Language style can also be a method of persuasion, manipulation and propaganda. Formal style (Saylor Foundation, 2014) can help the sender to persuade, and also create an illusion that the sender is more educated than he/she might be. The characters of the colloquial style (informal, everyday style) can show the person more positively, while the jargon gives the sender the ability to present himself as an expert in a certain field. Furthermore, the authors Cory Scherer and Brad Sagarin (2006, p. 143) conducted research in which it was proven that the use of curses at the beginning or at the end of speech is positively manifested in 
accepting the attitudes of the speech, which makes the usage of curse words a strong method of persuasion. Paralanguage refers to the height of the tones, the length of accent, the pause, the speed, the errors and other, numerous, elements in the communication. Using these elements, one is able to persuade someone into believing something is or is not true. Martin Remland (1993, p. 7) uses an example of an attorney in the courtroom and his use of non-verbal communication and paralanguage; he writes that moderate speed, speech quality and self-confident tone assist in delivering a persuasive speech. Praise on a personal level is at contrary to the attacks on a personal level and it is based on the human need for confirmation that something is done well. By using this method, the interlocutors' virtues can be emphasized; complimenting the physical appearance, the way of thinking or work. The suggestive use of clothing and colours assume that in different cultures, different colours or clothes are appropriate for same events. Clothing of certain colours can affect the perception of a person's credibility, for example in one culture a certain colour can be predominantly seen on a woman and almost never on a man. The usage of the exclusive language was added to this paper as the opposite method of the one that emphasizes the use of the inclusive language. Exclusive language refers to the use of words like "those", "others", "different", helping to exclude a person from a group or a community, while the division and difference between "us" and "them" is achieved (Saylor Foundation, 2014).

The research also included methods of using statements, praise on a personal level, and suggestive use of clothing and colours which were added while thinking about the context of the television series, moreover that this is a political drama and that some of the examples of the above stated methods might be used within a series. The statements refer to the quotation of well-known people (especially those deceased) or experts. As with the method of evidence, a person will more likely believe in something if it comes from a relevant source. This method is similar to the mentioned method, but it was extracted in order to distinguish the paraphrases used within the communication from the direct quotation used in order to persuade. Praise on a personal level is at contrary to the attacks on a personal level and it is based on the human need for confirmation that something is done well. By using this method, the interlocutors' virtues can be emphasized, for example by complimenting the physical appearance, the way of thinking or someone's work. The suggestive use of clothing and colours assume that, in different cultures, different colours or clothes are appropriate for the same events. Clothing of certain colours can affect the perception of a 
person's credibility, for example in one culture a certain colour can be predominantly seen on a woman and almost never on a man. This method was added thinking about the set of a series, which is placed in a political environment that is very strict when it comes to the protocol, more precisely, the usage of clothes.

As it is previously stated, our goal is to explore whether the methods of persuasion, manipulation and propaganda in the political drama House of Cards appear, especially when the main character breaks the "fourth theatrical wall", to see if Frank Underwood is trying to persuade and manipulate viewers in order to justify his means. By "drawing” the viewers into the narrative by addressing them directly and describing the situation, the transportation theory of persuasion could gain a new dimension - one in which fictitious characters "enter" the actual world of viewers (as oppose of the spectators "entering" the fictional world of the characters), adapting viewers to their ambitions and, finally, exploiting fictional power in the real world. In the following paragraphs, a short explanation of all the methods will be explained.

\section{Research}

\subsection{Methodology}

Persuasion, manipulation and propaganda dominate political life. The job of politicians is to persuade colleagues and opponents, to propose ideas and ideals to the people who elect them for political functions. The past, as well as the present, have shown that politicians do not quail even when they consciously manipulate the electorate. In order to answer the question whether the characters of the political drama House of Cards use methods of persuasion, manipulation and propaganda and if they do, which one, it was decided to subject to content analysis a number of sequences of this television series which display the ruthlessness of the political system in a democratic country in crisis.

According to Vesna Lamza Posavec (2011, p. 105), content analysis is "the process of studying and analysing verbal or nonverbal materials, which is used to perceive its properties and messages”. Lamza Posavec writes about two types of content analysis: qualitative and quantitative. This paper will, mostly, use the quantitative method of content analysis for which the author states that "it can be applied to different types and means of social 
communication: books, newspapers, songs, films, television and radio shows, web content, letters, legal regulations and laws, lyrics, artwork, etc." Since this article analyses the text of a television series, it is important to note that the term "text" can have ambiguous meaning. James Drisko and Tina Maschi $(2015$, p. 7$)$ explain the use of the term "text" in the content analysis and write that under the term "text" some consider only what we read, while others see "text" as what is being conveyed by an informational message. For researchers, the "text" refers to the concept of communication media that can be stored in various ways, including e.g. texts, sound recordings, television formats and movies and, due to the development of social media, electronic data. The authors warn that some information might be lost when transcribing speech, statements, or movie dialogues, as the paralingual elements cannot be detected in the process.

The unit of analysis of this work is a scene in which method(s) of persuasion, manipulation or propaganda is used and the scenes will be included in the analytical matrix that was created for the purpose of the research. The analytical matrix consists of ten research questions related to: the gender of the screenwriter of the episode, the use of the methods of persuasion, manipulation or propaganda, the gender and social status of the character who uses it and whether there are methods used while the protagonist addresses the viewers (usage of meta-reference). This matrix will not only provide information on whether the methods of persuasion are used in the series, but also the characteristics of the communication and communicators. The research will also show if one of the methods is used more in one gender than the other and also whether the characters that are persuading rely more on that kind of communication based on their social status. The gathered data will, thus, represent qualitative results of the research.

For this research, an equiprobability systematic sampling method was used, where the unit is selected by random number or a random number generator (Dumičić, Cvetkovič, 2007, p. 317). Out of the 52 episodes, the decision was made to analyse one quarter of them, more precisely, thirteen episodes. The random number table between the first, the second and the third episodes was used in order to define the starting episode. Thus, the survey sample consists of episodes: 1, 5, 9, 13, 17, 21, 25, 29, 33, 37, 41, 45 and 49. 


\subsection{Research Results}

The following pages of this paper will present the research results that will be displayed using tables and charts. Following each table and a chart there will be an interpretation of the results given, but also the data that are not provided in the tables. Moreover, most often used methods by the gender of the persuader and by the social ranking will be presented and some of them will be explained by giving an example from the television series.

Table 1. Usage of the persuasion, manipulation and propaganda methods in House of Cards

\begin{tabular}{|c|c|c|}
\hline Methods used & $\mathbf{N}$ & $\begin{array}{l}\text { Percentage of the total } \\
\text { number of methods used }\end{array}$ \\
\hline Analogy & 16 & 5.7 \\
\hline Anecdote & 5 & 1.8 \\
\hline Appeal to emotions & 16 & 5.7 \\
\hline Appeal to family values & 6 & 2.1 \\
\hline Appeal to fear and insecurity & 32 & 11.4 \\
\hline Appeal to group loyalty & 12 & 4.3 \\
\hline Appeal to hip-pocket nerve & 2 & 0,7 \\
\hline Appeal to patriotism & 8 & 2.9 \\
\hline Appeal to self-interest & 7 & 2.5 \\
\hline Appeal to the law and a sense of justice & 10 & 3.6 \\
\hline Appeal to tradition and customs & 2 & 0.7 \\
\hline Attack on a personal level & 60 & 21.4 \\
\hline Clichés & 6 & 2.1 \\
\hline Connotation & 0 & 0 \\
\hline Evidence & 8 & 2.9 \\
\hline Generalization & 2 & 0.7 \\
\hline Humour & 7 & 2.5 \\
\hline Language style & 7 & 2.5 \\
\hline Overstatement & 1 & 0.4 \\
\hline Paralanguage & 7 & 2.5 \\
\hline Praise on a personal level & 25 & 8.9 \\
\hline Repetition & 2 & 0.7 \\
\hline Rhetorical question & 3 & 1.1 \\
\hline Statements & 9 & 3.2 \\
\hline Suggestive use of clothing and colours & 2 & 0.7 \\
\hline The usage of exclusive language & 4 & 1.4 \\
\hline The usage of inclusive language & 21 & 7.5 \\
\hline Total & 280 & 100 \\
\hline
\end{tabular}


From Table 1 it is apparent that, in the 13 analysed episodes of the political drama House of Cards, the use of methods of persuasion, manipulation and propaganda was noticed 280 times, which tells us that the characters of this political drama use the above-mentioned methods quite often. The most commonly used method is the attack on a personal level that appeared in the analysed scenes 60 times or $21.4 \%$ of all the used methods. The second most commonly used method is the appeal to fear and insecurity, shown in 32 scenes, or $11.4 \%$ of all cases. The third most frequent method is the praise on a personal level and it was used 25 times or in $8.9 \%$ of the recorded scenes in which methods of persuasion are used. Furthermore, the method of using the inclusive language, characterized by the use of words like "we", "together" or words that involve a person with a certain group or community, was used in 21 scenes or in $7.5 \%$ of the analysed cases. Methods of analogy and appeal to emotions were equally used in $5.7 \%$ of all scenes in which persuasive methods were used. As the subject of this series is political, it is not surprising that some of the most commonly used methods of persuasion, manipulation and propaganda are attack on a personal level and appeal to fear and insecurity. Using such, primarily negative, methods among political actors of a democratic society implicitly points to criticism of such a system and casts distrust on the audience. Even the method of personal praise can be considered a negative method in the context of this political drama if we take into account the context in which it is used, which is the flattery and deception of the interlocutor in order to gain and take advantage of his trust.

As an example of the scene in which appeal to fear and insecurity is used, we point out the $4^{9^{\text {th }}}$ episode, in which US President Frank Underwood, talks with the Secretary of State, Catherine Durant, and confesses to her that he is responsible for the death of a journalist, Zoe Barnes, and Representative, Peter Russo. Finally, he turns it into a joke and uses the method of an appeal to fear and insecurity by saying hypothetically that in the case of necessity he can do the worst - kill all those who stand in his way, causing a fear noticed in verbal and non-verbal communication of Catherine Durant. Some other persuasion methods are used in this scene, such as the use of paralingual features (change of speed, rhythm and colour of the voice, the usage of pauses while talking, etc.) to convince her that his threats are serious. In this particular scene, it is easy to determine that this is manipulation and not persuasion. The protagonist gives an ultimatum to Catherine Durant and until the end of the episode we see that she is a subject of his manipulation and that she completely agrees to his conditions. 
Table 2. Usage of the persuasion, manipulation and propaganda methods by episode, by the gender of a character and by the gender of the screenwriter for the episode

\begin{tabular}{|c|c|c|c|c|c|c|}
\hline Episode & Gender of a screenwriter & Total per episode & $\delta^{2}$ & q & ${ }^{7}$ in $\%$ & in $\%$ \\
\hline 1 & 0 & 27 & 20 & 7 & $74.1 \%$ & $25.9 \%$ \\
\hline 5 & q & 30 & 30 & 0 & $100 \%$ & $0 \%$ \\
\hline 9 & $\hat{o}, \hat{\sigma}$ & 23 & 22 & 1 & $95.7 \%$ & $4.3 \%$ \\
\hline 13 & 0 & 9 & 5 & 4 & $55.5 \%$ & $44.5 \%$ \\
\hline 17 & q & 14 & 4 & 10 & $28.6 \%$ & $71.4 \%$ \\
\hline 21 & $\hat{0}$ & 11 & 5 & 6 & $45.4 \%$ & $54.6 \%$ \\
\hline 25 & $\hat{0}^{2}$ & 30 & 20 & 10 & $66.7 \%$ & $33.3 \%$ \\
\hline 29 & $\sigma^{2}$ & 10 & 8 & 2 & $80 \%$ & $20 \%$ \\
\hline 33 & $\hat{0}$ & 7 & 6 & 1 & $85.7 \%$ & $14.3 \%$ \\
\hline 37 & q & 48 & 15 & 33 & $31.2 \%$ & $68.8 \%$ \\
\hline 41 & † & 15 & 8 & 7 & $53.3 \%$ & $46.7 \%$ \\
\hline 45 & ㅇ & 23 & 7 & 16 & $30.4 \%$ & $69.6 \%$ \\
\hline 49 & $\partial^{\lambda}, q$ & 33 & 13 & 20 & $39.4 \%$ & $60.6 \%$ \\
\hline Total & & 280 & 163 & 117 & & \\
\hline
\end{tabular}

According to the data from Table 2 and Figure 1, male characters use the methods of persuasion, manipulation and propaganda more often than females, in $58.2 \%$ of all cases. There are a total six analysed episodes for which the script was written (or co-written) by women. Female characters used the methods of persuasion, manipulation and propaganda predominantly in four out of six episodes for which women wrote (or co-wrote) the scripts. This suggests that female characters were given somewhat more power in the episodes written by women, which was to be expected. 


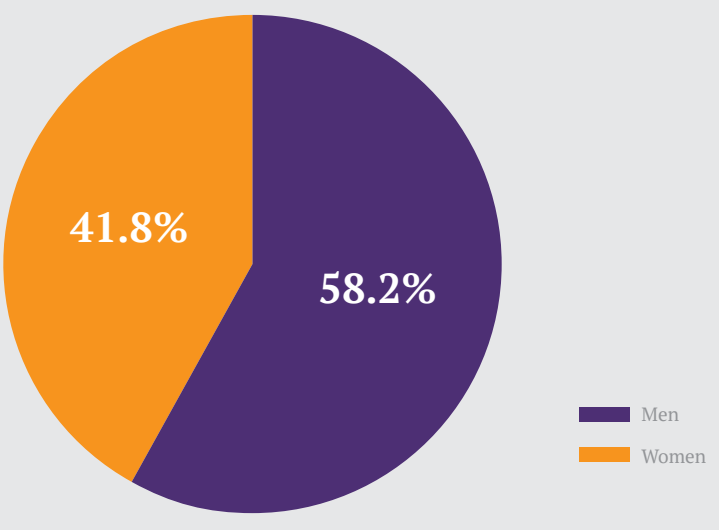

Figure 1. Usage of the persuasion, manipulation and propaganda methods by gender

The research has shown that the male characters most often used the following methods: the attack on a personal level (14.1\%), appeal to fear and insecurity (11.6\%), praise on a personal level (10.4\%) and analogy (9.8\%), while no examples of using generalization, connotation, overstatement and suggestive use of clothing and colours were found. Female characters, just as their male counterparts, used the attack on a personal level most frequently (31.6\%). The other most commonly used methods by women in order to persuade and manipulate were appeal to fear and insecurity (11.1\%) and, not surprisingly regarding the stereotypical gender characterization of women as a more emotional gender, appeal to emotions (9.4\%).

An example for the usage of the persuasion method appeal to emotions with female character is a scene from episode 17. In that scene, Frank's close associate Jackie Sharp, who took over his position of a House Majority Whip in the United States House of Representatives, tries to convince Representative Donald Blythe and his team to vote for bill proposals. Together with her associates, she enters the room in which Blythe and his team are bringing boxes full of blank papers, for which she states contain lists of names of all US citizens whose lives, if the proposed laws would not be enacted, would be impacted - student loans would not be paid, people might lose their jobs, post-war psychological counselling would not be funded, etc. After her monologue, there is a clear sense of guilt showing on Donald Blythe's face, which eventually affected his attitude and behaviour. 

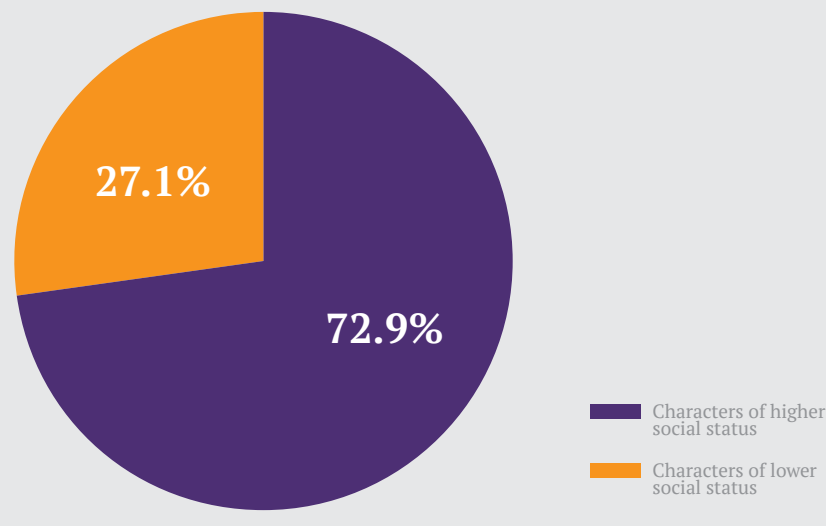

Figure 2. Usage of the persuasion, manipulation and propaganda methods by social status

If we compare whether the characters of higher or lower social status use more persuasion, manipulation, and propaganda methods, it is expected that, because of differences in power, the characters with a greater level of power are more able to manipulate the environment as opposed to their subordinates. The research showed that both types of characters use the most common methods of persuasion that we have mentioned so far - the attack on a personal level (characters of higher social status used it $21.1 \%$ and the ones of the lower status used it $22.4 \%$ of the time) and the appeal to fear and insecurity (10.3\% with the characters of higher social status and $14.5 \%$ with the characters of lower social status), although it was expected that the characters who had less social power would more often use the appeal to the law and a sense of justice, which ranked in fourth place (7.9\%) of the most used methods of persuasion.

In the case of characters of a higher social status, they used inclusive language in $7.8 \%$ of the time they persuaded, manipulated or propagated. As an example, the scene from episode 49, in which the Secretary of State, Catherine Durant addresses the electorate; thus in this scene we can see propaganda at the political gathering. After thanking all the delegates for considering her nomination for US Vice President, she informs everyone gathered that she will not participate in the elections and asks them to support Claire Underwood as a candidate together with her. In the end, her persuasion of the electorate results in Claire Underwood 
becoming a candidate for Vice President of the United States, joining the campaign ticket together with her husband.

In addressing the viewers within the framework of meta-references, used exclusively by the series protagonist Frank Underwood, the most commonly used method is an analogy (81.3\%), followed by statements (12.5\%) and anecdotes (6.2\%). An example is the method of analogy from episode 9 in which Frank Underwood gives secret information from the White House to journalist Zoe Barnes, with whom he is having a secret affair. In this scene she decides to end this unrelenting love affair and leaves the scene. In the next frame, Frank addresses the viewers directly and explains to them what Zoe Barnes was for him: "She was never more than a faint blip on my radar. We've served each other's purpose. She wants to be an adult. Let us see how she can fly when she leaves the nest." With this analogy Frank clearly reveals to the viewers that Zoe is a mere tool that he uses in order to achieve his goals.

Since the analogy is characterized by an explanation of some content in simple image-based terms, we can correlate it with the transportation theory. Namely, in simplifying the narrative context, there is certainly a greater possibility for the viewer to be transported to the narrative of a television series. If the viewer is directly addressed and the character is aware of the fact that we follow his life, the possibility of transportation is even greater. Anecdotes and method of statements are the methods of persuasion for which it can be said that deepen the relationship between character and the viewers. It can also be considered that the main character of the analysed series, using meta-reference, "draws in" the viewer deeper into the narrative of the television series, which potentially opens up new possibilities for further research of meta-references within the television narrative and expanding the transportation theory by adding to it the element of "direct drawing into narrative".

Frank Underwood, through the use of meta-references, makes it known to viewers that he is aware that someone is watching his life and he wants to clarify and justify his actions to the observer. Even if he is aware that he is doing something wrong, Underwood is addressing the viewers in a way that implies that they fully understand how the current political system works. He is dishonest, corrupt, leads his politics behind the closed doors, and appeases various powerful interest groups whose desires are more important than the ones of citizens and public interest, which points to the crisis of democracy, and in some ways confirms Chomsky's deliberation of a manufacturing consent. 


\section{Conclusion}

Persuasion, manipulation and propaganda are the omnipresent phenomena of human communication from ancient times to the present day. There are countless methods used in that kind of communication and the person who transmits persuasive messages needs to understand whether they behave ethically or unethically in relation to the receiver of the message. Knowledge is critical in developing critical thinking and the knowledge about persuasion, manipulation and propaganda can be used to recognize such communication and respond appropriately to it. The unconscious learning of these subjects through television content, as learning through series similar to House of Cards, the viewer is potentially guided to use what he saw while communicating with others, but without the real knowledge of persuasion it can eventually lead to an increasing gap and a crisis in interpersonal communication.

As the transportation theory of persuasion states, the higher the emotional bond with the characters is, the higher the possibility for the viewers to "transport" within the narrative. By breaking the "fourth wall" and creating a more intimate, almost friendly relationship with viewers, Frank Underwood wants to explain how we are just observers of a passive political system and not its creators. Because the viewers create strong emotional bonds with Underwood, they do not consider him a villain, and for many he is even a hero. They may also consider that the behaviour of the protagonists is desirable in today's world, especially if they want to achieve certain political ambitions. The idea of democracy and citizens' rights to choose political actors who work for the benefit of society comes to question. While in the past antagonists were not loved and the viewers wanted for good to triumph over evil, it seems as if the producers and screenwriters often want us to love, understand, and to provoke a deeper relationship with the antihero protagonists, who are no longer the saviours of the world, but rather those who contribute to its crisis. Considering that the series reflects the sociocultural reality and change, this television series is a sophisticated irony of the democratic political system that is in a crisis, the creation of relationship with the antihero protagonist can contribute to moral relativism, and the attitude that the viewers are just puppets in the hands of fictional democracy and its politicians. If the series depicts protagonists who use politics to achieve personal and immoral goals, narrative engagement can contribute to an even greater political apathy that is currently affecting most of the Western population, which can be confirmed in the decreasing voting turnout around the world. 
There is still not enough research focusing on the analysis of communication and persuasion within the narrative of television series, which is why this paper is a potential contribution to the academic community. What needs to be examined further are television series viewers and their awareness of the use of methods of persuasion, manipulation, and propaganda within television narratives, as well as the influence of these methods on their attitudes and behaviours. It is especially important to study the fans of television series to understand whether they view, for example, the use of meta-references as an attempt to persuade them or just as an interesting element of their favourite television series, and if they can relate more to the narrative of a television series because of the direct addressing of the main character, which potentially contributes to the expanding of the transportation theory of persuasion by adding to it the element of "direct drawing into narrative".

\section{Reference List}

- Auter, P. J., Davis, D. M. (1991). When Characters Speak Directly to Viewers: Breaking the Fourth Wall in Television. Journalism Quaterly, 68, 165-171.

- Bennett, B. (2012). Logically Fallacious: The Ultimate Collection of Over 300 Logical Fallacies. USA: eBookilt.com.

- Bernays, E. (1928). Propaganda. New York: Horace Liveright.

- Bond, B. J., Calvert, S. L. (2014). Children's parasocial relationships. In: Jordan, A. B., Romer, D. (Eds.), Media and the well-being of children and adolescents (pp. 187-200). Oxford: Oxford University Press.

- Branch, S., Wilson, K., Agnew, C. (2013). Committed to Oprah, Homer, or House: Using the Investment Model to Understand Parasocial Relationships. Psychology of Popular Media Culture, 2, 96-109.

- Breuer, I., Napthine, M. (2008). Persuasive Language in Media Texts. Australia: Insight Publications.

- Buonanno, M. (2006). L'età della televisione. Roma/Bari: Laterza.

- Casetti, F., Di Chio, F. (2001). Analisi della televisione. Milano: Strumenti Bompiani.

- Chomsky, N., Herman, E. S. (1988). Manufacturing Consent: The Political Economy of the Mass Media. New York: Pantheon Books.

- Dibble, J. L., Hartmann, T., Rosaen, S. F. (2016). Parasocial interaction and parasocial relationship: Conceptual clarification and a critical assessment of measures. Human Communication Research, 42 (1), 21-44.

- Drisko, W. J., Maschi, T. (2015). Content Analysis. New York: Oxford University Press.

- Dumičić, K., Cvetkovič, B. (2007). Dizajni uzoraka primjenjivi u revizijskim testovima. Zbornik Ekonomskog fakulteta u Zagrebu, 5 (1), 313-330.

- Eyal, K., Cohen, J. (2006). When Good Friends Say Goodbye: A Parasocial Breakup Study. Journal of Broadcasting \& Electronic Media, 50, 502-523.

- Esquenazi, J. (2009). La vérité de la fiction. Paris: Hermès-Lavoisier.

- Esquenazi, J. (2010). Televizijske serije. Beograd: Clio.

- Fiske, J., Hartley, J. (1978). Reading Television. London: Metguen.

- Franklin, C. (2014). House of Cards: Chapter 14. Los Gatos: Netflix. 
- Grasso, A. (2007). Buona maestra: Perché i telefilm sono diventati più importanti dei libri e del cinema. Milano: Mondadori.

- Green, M. C., Brock, T. C. (2000). The role of transportation in the persuasiveness of public narratives. Journal of Personality and Social Psychology, 79 (5), 701-721.

- Harré, R. (1985). Persuasion and Manipulation. In: van Dijk, T. A. (Ed.), Discourse and Communication: New Approaches to the Analysis of Mass Media Discourse and Communication (pp. 126-142). Berlin: Walter de Gruyter.

- Hartmann, T., Goldhoorn, C. (2011). Horton and Wohl revisited: Exploring viewers' experience of parasocial interaction. Journal of Communication, 61, 1104-1121.

- Hartmann, T. (2016). Parasocial interaction, parasocial relationships, and well-being. In: Reinecke, L., Oliver, M. B. (Eds.), The Routledge Handbook of Media Use and Well-Being: International Perspectives on Theory and Research on Positive Media Effects (pp. 131-144). New York: Routledge.

- Hoffner, C., Buchanan, M. (2005). Young Adults' Wishful Identification With Television Characters: The Role of Perceived Similarity and Character Attributes. Media Psychology, 7 (4), 325-321.

- Horton, D., Strauss, A. L. (1957). Interaction in audience-participation shows. The American Journal of Sociology, 62, 579-587.

- Horton, D., Wohl, R. (1956). Mass communication and para-social interaction: Observations on intimacy at a distance. Psychiatry, 19, 215-229.

- Hsu, C.-T., Conrad, M., Jacobs, A. M. (2014). Fiction feelings in Harry Potter: haemodynamic response in the mid-cingulate cortex correlates with immersive reading experience. Neuroreport, 25, 1356-1361.

- Lakey, B., Cooper, C., Cronin, A., Whitaker, T. (2014). Symbolic providers help people regulate affect relationally: Implications for perceived support. Personal Relationships, 20, 404-419.

- Lamza Posavec, V. (2011.) Kvantitativne metode istraživanja: Anketa i analiza sadržaja. Zagreb: Hrvatski studiji Sveučilišta u Zagrebu.

- McKeown, B., Thomas, B. D., Rhoads, C. J., Sundblad, D. (2015). Falling hard for Breaking Bad: An investigation of audience response to a popular television series. Participations: Journal of Audience \& Reception Studies, 12 (2), 147-167.

- Moran, C. C. (1996). Short-term mood change, perceived funniness and the effect of humour stimuli. Behavioral Medicine, 22 (1), 32-38.

- Newcomb, H. (1988). One Night of Prime Time. In: Carey, J. W. (Eds.), Media, Myths and Narrative (pp. 88-112). London: Sage.

- O’Connor, A. (Ed.) (1989). Raymond Williams on Television: Selected Writings. London, New York: Routledge.

- Perloff, R. M. (2002). The Dynamics of Persuasion: Communication and Attitudes in the 21st Century. USA: Lawrence Erlbaum Associates, Inc.

- Pratkanis, A., Aronson, E. (1992). Age of propaganda: The everyday use and abuse of persuasion. New York: Freeman.

- Remland, S. M. (1993). The Importance of Nonverbal Communication in the Courtroom. Communication conference paper, West Chester: West Chester University.

- Rousseau, J. J. (1762/2008). The Social Contract. Cosimo, Inc.: USA.

- Scherer, R. C., Sagarin J. B. (2006). Indecent influence: The positive effects of obscenity on persuasion. Social Influence, 1 (2), 138-146.

- Schiappa, E., Allen, M., Gregg, P. B. (2007). Parasocial relationships and television: A meta-analysis of the effects. In: Preiss, R. W., Gayle, B. M., Burrell, N., Allen, M., Bryant, J. (Eds.), Mass media effects research: Advances through meta-analysis (pp. 301-314). Mahwah, NJ: Erlbaum Associates.

- Stevenson, J. (1995). The Fourth Wall And The Third Space. New York: Centre for Playback Theatre.

- Van Laer, T., de Ruyter, K., Visconti, L. M., Wetzels, M. (2014). The Extended Transportation-Imagery Model: A Meta-Analysis of the Antecedents and Consequences of Consumers' Narrative Transportation. Journal of Consumer Research, 40 (5), $797-817$.

- Verbruggen, J. (2016). House of Cards: Chapter 52. Los Gatos: Netflix.

\section{Internet Sources}

- Drama (2016). thesciptlab.com. Retrieved from: http://thescriptlab.com/screenplay/genre/drama\#. 2 August 2016

- Persuasive Techniques (2014). Saylor Foundation, Washington, D.C.: USA. Retrieved from: http://www.saylor.org/site/wpcontent/uploads/2014/01/K12ELA7-7.2.2-PersuasiveTechniquesHandout-BY-SA1.pdf. 17 July 2016. 


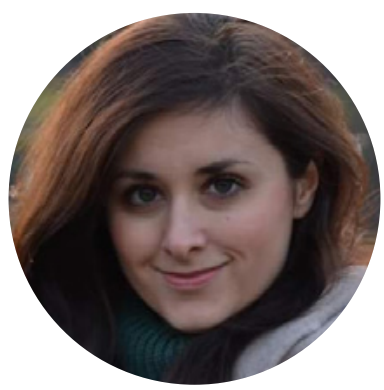

Irena Sever Globan

Irena Sever Globan graduated in Theology at the Catholic Theological Faculty (Zagreb) in 2004 while at the Faculty of Social Communication Sciences at the Pontifical Salesian University in Rome, Italy, she completed her $\mathrm{PhD}$ in 2011. Currently she is working as an Assistant Professor at the Department of Communication Studies of the Catholic University of Croatia in Zagreb where she teaches subjects related to mass media and film studies. Her specific areas of research and interest are related to film studies, television drama, popular culture and religion, and representation of women in media. She has participated in more than ten international conferences and has published 13 scientific papers.

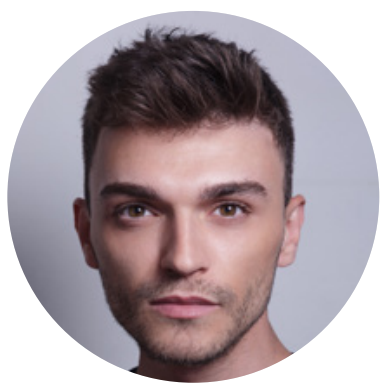

Marko Ezgeta

Marko Ezgeta earned his master's degree in communication science in 2016. Throughout his education he got involved in film and developed an affection for motion pictures and television series. As he is strongly interested in political systems and communication strategies in politics, his research interests focus on the political communication, especially in the audio-visual media. He is currently pursuing a corporate career, working in an integrated communications agency and is hoping to enrol a Ph.D. programme either in diplomacy and international relations or in communication science. 